\title{
Saccharomyces cerevisiae, bentonite, and kaolin as adsorbents for reducing the adverse impacts of mycotoxin contaminated feed on broiler histopathology and hemato-biochemical changes
}

\author{
Toochukwu Ejiofor $^{1}$ (D) Anthony Christian Mgbeahuruike ${ }^{\text {(D) }}$, Chiamaka Ojiako ${ }^{1}$ (D), Ashang Micheal Ushie ${ }^{1}$ (D),

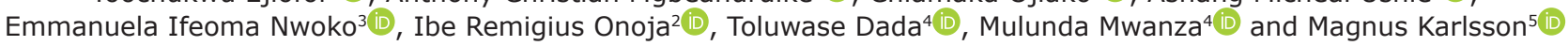 \\ 1. Department of Agric Education, Faculty of Vocational Technical Education, University of Nigeria, 410002 Nsukka, \\ Nigeria; 2. Department of Veterinary Pathology and Microbiology, Faculty of Veterinary Medicine, University of Nigeria, \\ 410002, Nsukka, Nigeria; 3. Department of Human Kinetics and Physical Education, Faculty of Education, University of \\ Nigeria, 410002 Nsukka, Nigeria; 4. Department of Animal Health, Faculty of Natural and Agricultural Sciences, \\ North-West University, Mafikeng Campus, Private Bag X 2046 Mmabatho, 2735, South Africa; 5. Department of Forest \\ Mycology and Plant Pathology, Swedish University of Agricultural Sciences, SLU, Box 7026, SE-75007 Uppsala, Sweden. \\ Corresponding author: Anthony Christian Mgbeahuruike, e-mail: anthony.mgbeahuruike@unn.edu.ng \\ Co-authors: TE: toochukwu.ejiofor@unn.edu.ng, CO: chiamaka.ojiako@unn.edu.ng, AMU: michaelashang@yahoo.com, \\ EIN:nuellaifeoma@gmail.com, IRO: remigius.onoja@unn.edu.ng, TD:adedad@gmail.com, \\ MM: mulunda.mwanza@nwu.ac.za, MK: magnus.karlsson@slu.se
}

Received: 25-06-2020, Accepted: 20-11-2020, Published online: 05-01-2021

doi: www.doi.org/10.14202/vetworld.2021.23-32 How to cite this article: Ejiofor T, Mgbeahuruike AC, Ojiako C, Ushie AM, Nwoko EI, Onoja IR, Dada T, Mwanza M, Karlsson M (2021) Saccharomyces cerevisiae, bentonite, and kaolin as adsorbents for reducing the adverse impacts of mycotoxin contaminated feed on broiler histopathology and hemato-biochemical changes, Veterinary World, 14(1): 23-32.

\begin{abstract}
Background and Aim: Saccharomyces cerevisiae, bentonite and kaolin were used to reduce the adverse effects of moldcontaminated diet on broilers. The aim of the study was to evaluate the impact of $S$. cerevisiae, bentonite, and kaolin in reducing the adverse effects of mold (fungal) contaminated diet on broilers. Specifically, we investigated the histopathological, hematological, and serum biochemical changes associated with broilers fed mold-contaminated diets supplemented with these three adsorbents. We also isolated and identified the common fungal contaminants in the poultry feeds as well as the mycotoxins they produced.

Materials and Methods: Hundred broilers (3-weeks-old) were randomly grouped into five dietary treatments, basal feed (negative control), feed contaminated with mold, mold-contaminated feed $+S$. cerevisiae, mold-contaminated feed + bentonite, and mold-contaminated feed+kaolin. The fungal contaminants in the feeds were isolated and molecularly identified while the mycotoxins in the feed where analyzed using high-performance liquid chromatography. Blood samples of birds from each group were analyzed for hematology and serum biochemistry. The liver, spleen, kidney, and bursa of Fabricius of the birds were excised and analyzed for histopathological changes.

Results: The most common fungal contaminants in the feeds were Penicillium (33.3\%) species, followed by Aspergillus species $(22.2 \%)$. The mold-contaminated feed had the highest number of fungal contaminants, $55.6 \%$, while the negative control (basal feed group) had none. Total aflatoxin and deoxynivalenol were high in the mold-contaminated feed $(53.272 \mu \mathrm{g} / \mathrm{kg}$ and $634.5 \mu \mathrm{g} \mathrm{kg}$, respectively), but these were reduced by the addition of adsorbents to the feed. The birds fed mold-contaminated feed had significantly $(\mathrm{p}<0.05)$ reduced red blood cell count counts, packed cell volume, and hemoglobin but increased white blood cell count compared to the negative control. Liver enzyme activity (alanine transaminase, aspartate aminotransferase, and alkaline phosphatase) and cholesterol concentration increased significantly $(p<0.05)$ in the group fed mold-contaminated feed while the serum albumin and total protein decreased significantly $(p<0.05)$ in comparison with the negative control. Adverse histopathological changes were observed in the liver, kidney, spleen, and bursa of Fabricius in the group fed mold-contaminated feed. Addition of $S$. cerevisiae, bentonite or kaolin in the mold-contaminated feed ameliorated these toxic effects.
\end{abstract}

Conclusion: The observed histopathological lesions were consistent with mycotoxicosis in birds and were mild in the adsorbent treated groups. Kaolin had a higher protective effect against mycotoxicosis than the two other adsorbents.

Keywords: adsorbent, feed, mold, mycotoxin, pathology, Saccharomyces cerevisiae.

\section{Introduction}

The world poultry sector has undergone a huge expansion due to the demand for poultry meat, making

Copyright: Ejiofor, et al. Open Access. This article is distributed under the terms of the Creative Commons Attribution 4.0 International License (http://creativecommons.org/licenses/by/4.0/), which permits unrestricted use, distribution, and reproduction in any medium, provided you give appropriate credit to the original author(s) and the source, provide a link to the Creative Commons license, and indicate if changes were made. The Creative Commons Public Domain Dedication waiver (http://creativecommons.org/ publicdomain/zero/1.0/) applies to the data made available in this article, unless otherwise stated. it the fastest growing and most flexible of all livestock sectors [1]. The rapid expansion of this sector is partly as a result of quality feed formulation; and faster growth performance of birds caused by both genetic factors and better management conditions [2]. The Nigerian poultry industry has an annual growth rate of $2 \%$ and it has contributed so much to the development of the country in terms of food provision and employment generation. However, the industry faces a serious challenge due to poor processing of poultry feeds and feed contamination with mycotoxins [3]. 
In Nigeria, feed ingredients are bought locally by commercial feed companies during the production seasons and stored for a long period of time. The stored feed ingredients are used for feed production throughout the year. The long storage period predisposes the feed materials to fungal growth and mycotoxin contamination. Contamination of feed materials like grains by mycotoxins occurs either during the pre-harvest, harvest or during feed production, and storage. Mycotoxins are secondary metabolites of fungi found in grains and stored feed materials [4]. Some known mycotoxins that could have severe impacts on poultry health and performance are aflatoxins (AFs), ochratoxin A, T-2 toxins, zearalenone (ZEN), and deoxynivalenol (DON). High humidity and hot climatic conditions favor the growth of mycotoxin-producing fungi [5]. Some of the known mycotoxin producing fungi include Aspergillus which produces AF [6,7]. Fusarium species produce the mycotoxin ZEN which has estrogenic and immunotoxic properties [8,9]. Trichothecenes and DONs are produced by fungi of different genera such as Trichothecium, Stachybotrys, Myrothecium, Cephalosporium, Trichoderma, Penicillium, and Fusarium [8,9]. When mycotoxins are ingested in high doses, they can lead to acute clinical symptoms and severe damages to vital organs, damage to avian physiology as well as depression of the immune system of the affected birds [10]. Studies have shown that $\mathrm{AFB}$ could have a range of negative effects on poultry health, hematological, biochemical, and hepatorenal abnormalities [11-13].

The present study is significant because, there is need to search for locally available and cheap adsorbents, as means of decontaminating mycotoxin contaminated feed in low-income countries like Nigeria. Decontamination of poultry feeds can be done using chemical, physical, and biological approaches. Drying cereals before storage has been adopted because it reduces the high humidity content of feeds $[14,15]$. Furthermore, some bacteria that detoxify mycotoxins in the gut have been incorporated in feeds to prevent the absorption of such contaminants in the feed [15]. Other biological approaches involve the use of adsorbents or feed additives which bind mycotoxins, thereby preventing their absorption in the gastrointestinal tract [16]. Some commercially available adsorbents include aluminosilicates and esterified glucomannan derived from the cell wall of Saccharomyces cerevisiae [17]. However, locally available adsorbents such as fuller's earth, bentonite, and activated charcoal have been reported to be effective in feed decontamination [18]. Some studies have shown the effects of different adsorbents on mycotoxin contaminated animal feed [19]. Although the effect of many adsorbents such as $S$. cerevisiae, bentonite, and kaolin on contaminated feed has been extensively studied, there is a paucity of information on their comparative effect on mold-contaminated diet in birds.

$S$. cerevisiae and other microorganisms have been reported to act as sequestering agents in the gastrointestinal tract of animals through the formation of mycotoxin-microorganism complex [20-22]. S. cerevisiae has been used in other studies as probiotic feed additives and for biodegradation of mycotoxin contaminated feeds [23,24]. Bentonite is structurally composed of several minerals, including montmorillonite, quartz, feldspar, volcanic glass, organic matter, and gypsum or pyrite. Bentonite has been used in $\mathrm{AF}$ decontamination of poultry feeds in other studies [19]. Kaolin is a plastic raw material consisting of the clay mineral kaolinite. Kaolin is formed through intensive weathering of rocks rich in feldspar (granite, arkose, certain types of orthogneisses, and migmatites). Due to its adsorbent capability and lack of primary toxicity, kaolin is used to prevent or ameliorate the adverse effects of many toxic agents. Kaolin clay minerals have been demonstrated to reduce diarrhea in animal production, improve feed conversion ratio, and health of many livestock species due to their specific adsorption potential of many feed mycotoxins [25].

The aim of the study was to evaluate the impact of $S$. cerevisiae, bentonite, and kaolin in reducing the adverse effects of mold (fungal) contaminated diet on broilers. Specifically, we investigated the histopathological, hematological, and serum biochemical changes associated with broilers fed mold-contaminated diets supplemented with these three adsorbents. We also isolated and identified the common fungal contaminants in the poultry feeds as well as the mycotoxins they produced.

\section{Materials and Methods}

\section{Ethical approval}

The broilers used in this experiment were handled in accordance with the revised version of the Animals Scientific Procedures Act of 1986 for the care and use of animals for research purposes. Furthermore, approval to conduct the study was obtained from the head of the Department of Microbiology and Pathology, Faculty of Veterinary Medicine, University of Nigeria Nsukka. The findings from this study are reported below with strict compliance to the procedures outlined in ARRIVE guidelines for reporting in vivo experiments in animal research [26].

\section{Study area and period}

The experiment was conducted at the University of Nigeria Nsukka Agric farm. Nsukka is a small town in Enugu State located on latitude $6^{\circ} 51^{\prime} 21^{\circ} \mathrm{N}$ and longitude $7^{\circ} 51^{\prime} 24^{\circ} \mathrm{N}$. The total land area is $1,810 \mathrm{~km}^{2}$ and it has a population of 309,633 with three senatorial zones [27]. The study was conducted from June to November 2019.

\section{Experimental birds}

One hundred (3-weeks-old) Arbor acre broilers purchased from Okay Farms Nsukka were used for the study. The broilers were marked on the legs and each group was housed in a room-sized pen for acclimatization. During the period of acclimatization, the 
broilers were fed freshly prepared uncontaminated starter mash, formulated according to the revised version of the protocol for nutrient requirements of poultry [28]. Routine treatments and vaccinations were given to the broilers during the period of acclimatization. The broilers were moved to separate pens on the $4^{\text {th }}$ week and were allotted to five dietary treatments, with four replicates per treatment and five broilers per pen (replicate). They were exposed to $24 \mathrm{~h}$ light while the pens were maintained at environmental temperature. The birds were allowed free access to feed and water throughout the period of the experiment.

\section{Feed treatment and experimental design}

The poultry feeds used in this study were purchased from a commercial feed dealer at Ogige Market Nsukka. All the feeds were from the same source and they all had the same date of production. The feeds were mixed together and placed in a large dark, water/ air proof bag. Fungal growth and contamination of the feed were induced by sprinkling water on the contents of the bag until the feed was properly wetted and more than $30 \%$ moisture was obtained. The bag was sealed and stored in a room with a humidity of $50-60 \%$ and temperature range of $25-30^{\circ} \mathrm{C}$, until mold growth was visibly observed. After 2 months of storage, the mold-contaminated feeds were divided into four different bags, the first bag was used as the positive control without further treatment. The other three bags were further treated with $2 \mathrm{~g}$ of bentonite $/ \mathrm{kg}$ of the feed, $2 \mathrm{~g}$ of $S$. cerevisiae $/ \mathrm{kg}$ of the feed, and $2 \mathrm{~g}$ of kaolin $/ \mathrm{kg}$ of the feed, respectively. The locally prepared adsorbents were purchased at Joachim Laboratory Limited, University of Nigeria, Nsukka office. The feed additives were thoroughly mixed and the feeds were further stored for 2 weeks to allow the adsorbents to act properly on the mold-contaminated feeds. After 2 weeks, a freshly prepared feed, basal diet from the same source was purchased as a negative control and the feeds were served to the five groups of experimental birds for the entire period of the experiment.

\section{Mycotoxin measurement}

Mycotoxin analysis was carried out using high-performance liquid chromatography (HPLC) (model 600 pump, 717 autosampler) with an in-line degasser and model 470 scanning fluorescence detector. Mycotoxin was extracted as described in Bhatti et al. [19]. Briefly, approximately $10 \mathrm{~g}$ of each feed sample was ground with mortar and pestle and transferred to extraction tubes containing water and acetonitrile $(20: 80 \%, v / v)$. The solution was placed in a rotary shaker for $45 \mathrm{~min}$ for proper mixing and later subjected to the extraction process. For each sample, $1 \mathrm{~g}$ of sodium chloride and $20 \mathrm{~mL}$ of $\mathrm{n}$-hexane were added to the tube and thoroughly mixed together. The mixture was filtered using filter paper (Schleicher and Shuell, 5971/2) and the filtrate was centrifuged for $10 \mathrm{~min}$ at $4000 \mathrm{~g}$. The lower methanol phase was used for immune affinity cleanup while the upper hexane phase was discarded. About $40 \mathrm{~mL}$ of de-ionized water was diluted with an aliquot $(1 \mathrm{~mL})$ of the extract and mixed thoroughly. The resulting solution was purified on immunoaffinity columns (VicamAflaTest, VICAM, 313 Pleasant Street, Watertown MA, USA.) and the extract was further analyzed using reversephase HPLC (Shimadzu Corp.) with isocratic elution and fluorescence detection, after post-column derivatization with bromine by KOBRA CELL $\mathbb{}$ (Rhone Diagnostics, Glasgow UK). The total AF $\left(\mathrm{AFB}_{1}+\mathrm{AFB}_{2}+\mathrm{AFG}_{1}+\mathrm{AFG}_{2}\right)$ in the samples was measured alongside the mycotoxin, DON).

\section{Isolation of the fungal contaminants}

The fungal contaminants in the feed were isolated by the dilution plate technique [29]. One gram of feed sample from each treatment group was suspended in $9 \mathrm{~mL}$ of sterile distilled water and mixed thoroughly for $2 \mathrm{~min}$ by hand inversion. Approximately $0.1 \mathrm{~mL}$ aliquot of the suspension was plated in triplicates on potato dextrose agar (PDA) and the plates were incubated at $28^{\circ} \mathrm{C}$. After $48 \mathrm{~h}$ of incubation, the colonies in each plate were counted and recorded as the fungal load per sample and the colony-forming unit/g was calculated for each sample. Each fungal colony from the mixed culture in each plate was carefully picked with a sterile toothpick and transferred again into sterile and freshly prepared PDA plates for final purification [30]. The fungal colonies were isolated based on their morphological characteristics, such as color of isolate and physical appearance on the media [31].

\section{Molecular identification of the fungal contaminants} DNA extraction

Genomic DNA extraction from the fungal isolates was done using the Zymo Research kit (ZymoResearch fungal/Bacterial Soil Microbe DNA, D6005, USA), following the procedure described in other studies [32]. Briefly, a loopful of the fungal spores from 5 to 7 days old culture was scooped into the Bashing Bead ${ }^{\mathrm{TM}}$ lysis tubes and $750 \mu \mathrm{L}$ of the lysis solution was added to the tubes. The tubes were beaten in a bead beater at maximum speed for $14 \mathrm{~min}$ and centrifuged in a micro-centrifuge at $10,000 \times g$ for 1 min. Four hundred microliters of the supernatant were transferred into a collection filter tube which was centrifuged at $10,000 \times g$ for 1 min after which $1200 \mu \mathrm{L}$ of the binding buffer was added to enhance the binding of the toxins to the filter column. The mixture was further centrifuged in the column in the collection tube and the flow-through discarded. About $200 \mu \mathrm{L}$ and $500 \mu \mathrm{L}$ of pre-washed and washed buffers were added separately to each column, respectively, and centrifuged at the same conditions. Finally, $100 \mu \mathrm{L}$ of the DNA elution buffer was added to the column after washing and centrifuged to elute the DNA.

\section{Polymerase chain reaction (PCR) amplification of genomic DNA and sequencing}

The amplification of the Internal Transcribed Spacer Region (ITS rDNA) of the fungal isolates from 
the feed was carried out with PCR using the universal primers (Table-1) supplied by Inqaba biotechnical Industrial (Pty) Ltd. (Pretoria, South Africa). The amplification parameters included an initial denaturation at $94^{\circ} \mathrm{C}$ for $5 \mathrm{~min}$, followed by 30 cycles of $94^{\circ} \mathrm{C}$ for $35 \mathrm{~s}$, annealing at $58^{\circ} \mathrm{C}$ for $30 \mathrm{~s}$, and extension at $72^{\circ} \mathrm{C}$ for $25 \mathrm{~s}$, with a final extension at $72^{\circ} \mathrm{C}$ for $10 \mathrm{~min}$. The PCR amplicons were analyzed by electrophoresis on $1 \%(\mathrm{w} / \mathrm{v})$ agarose gel and visualized under UV light [33]. Sequencing of the purified PCR products was done at Inqaba Biotechnical Industrial (Pty) Ltd, Pretoria, South Africa with PRISM ${ }^{\mathrm{TM}}$ Ready Reaction Dye Terminator Cycle Sequencing Kit, using the dideoxy chain termination method. The sequenced samples were electrophoresed with a model ABI PRISM ${ }^{\circledR}$ 3500XL DNA Sequencer (Applied BioSystems, Foster City, CA, USA) following the manufacturer's instructions. Finch TV software version 1.4.0 (Geospiza, Inc. Seattle, WA, USA) was used for the analysis of chromatograms, resulting from the sequencing. The consensus ITS rDNA sequences obtained were Blasted in the National Center for Biotechnology (NCBI) database (www.ncbi.nlm.nih.gov) with the Basic Local Alignment Search Tool for homology to identify the probable organisms in question [34]. The sequences were later deposited in the GenBank for accession number allocation.

\section{Sample collection from the experimental birds}

The sampling from the experimental birds was done during the $10^{\text {th }}$ week of the experiment. Three birds per pen were randomly selected; blood samples were collected from the jugular veins of the selected birds into heparinized tubes and non-heparinized tubes for hematology and serum biochemistry, respectively. They were humanely sacrificed and dissected for collection of liver, kidney, spleen, and bursa of Fabricius samples. Two samples each were collected for each organ and were fixed in 10\% buffered formalin for histopathology.

\section{Hematological and serum biochemical analysis}

The packed cell volume (PCV) was determined using the Microhematocrit method while the red blood cell (RBC) count and total white blood cell (WBC) count were determined using the hemocytometer method [35]. Hemoglobin ( $\mathrm{Hb})$ concentration was determined using Drabkin's reagent assay method for $\mathrm{Hb}$ concentration. The serum biochemical parameters were determined using Quimica Clinica Aplicada test kits (Quimica Clinica Aplicada, Spain) and a spectrum Lab 21A spectrophotometer (Spectrum Lab, England). The activity of the liver enzymes, alkaline phosphatase (ALP), alanine transaminase (ALT), and aspartate

Table-1: Primer sequences.

\begin{tabular}{ll}
\hline ITS 1-Forward primer & TCC GTA GGT GAA CCT GCG G \\
ITS 4-Reverse primer & TCC TCC GCT TAT TGA TAT GC
\end{tabular}

Primer sequences used for the amplification of the internal transcribed region of the fungal gene aminotransferase (AST) was determined using commercial kits (ALP [AP307], AST [AS101], and ALT [AL100] - Randox, United Kingdom) and a spectrophotometer. ALP was measured at $405 \mathrm{~nm}$ while AST and ALT were measured at $546 \mathrm{~nm}$. The total serum protein and serum globulin were obtained, following the procedure detailed in Rezende et al. [36]. The serum cholesterol was determined by enzymatic colorimetric method [37].

\section{Histopathology}

Histopathological examination of the excised organs was carried out as described by Bancroft et al. [38]. Briefly, the liver, kidney, spleen, and bursa of Fabricius were obtained from the dissected birds at the end of the experiment $\left(10^{\text {th }}\right.$ week $)$ and fixed in $10 \%$ neutral buffered formalin. The fixed tissues were then passed through several concentrations of alcohol and xylene before embedding in paraffin wax. The embedded tissues were sectioned using a rotary microtome at a thickness of $5 \mu \mathrm{m}$. The sections were picked and floated on a water bath and then picked with a pre-labeled slide. The slides were dried on a hot plate at a temperature of $5-10^{\circ} \mathrm{C}$ above the melting point of wax, dewaxed with xylene, and hydrated through descending grades of alcohol before staining with hematoxylin and eosin method to demonstrate general tissue structure. The slides were then mounted on coverslips with DPX devoid of air bubbles. The specimens were examined and photomicrographs were captured using a Motic Images plus 2.0 digital cameras (Motic China Group Ltd. 1999-2004).

\section{Statistical analysis}

Statistical analysis of the data was performed using SPSS statistics 23.0 version software (IBM Corp, USA). Multiple comparisons were performed using one-way analysis of variance, followed by post $h o c$ test and significant differences were determined at $\mathrm{p}<0.05$.

\section{Results}

\section{Biodiversity of the fungal contaminants in the feed}

Initial culture of the feed samples produced fungi with mixed morphologies. Pure culture of each fungal isolate led to the isolation of a plethora of fungi with discernible identity. Six major genera of fungi were found in all the feeds; Epicoccum, Rhizomucor, Pichia, Penicillium, Aspergillus, and Beauveria (Table-2). The mold-contaminated feed, contaminated feed supplemented with $S$. cerevisiae, and contaminated feed supplemented with kaolin had the highest representation of fungal contaminants $(55.6 \%)$ each (Table-2). The culture samples from the basal feed produced no fungal contaminant. Sequencing of the fungal ITS region for identification to the species level and blast search at the NCBI revealed three species of Penicillium; Penicillium bilaiae, Penicillium crustosum, and Penicillium glabrum; two species of Aspergillus; Aspergillus niger and Aspergillus 
Fumigatus; and one species each for the other fungal isolates (Table-3). The sequences of the identified fungi were deposited at GenBank in NCBI with accession numbers as indicated in Table-3.

\section{Mycotoxin concentration in the feed}

The basal diet had the lowest concentration of total AF $(16.874 \mu \mathrm{g} / \mathrm{kg})$ while the mold-contaminated feed without any adsorbent had the highest concentration $(53.272 \mu \mathrm{g} / \mathrm{kg})$. The total AF concentration was considerably reduced in the feeds supplemented with adsorbents. The contaminated feed treated with kaolin had the highest reduction in AF, followed by the bentonite treated feed (Table-4). The concentration of DON was lowest in the basal feed $(26.48 \mu \mathrm{g} / \mathrm{kg})$ and highest in the mold-contaminated feed $(634.5 \mu \mathrm{g} / \mathrm{kg})$. The mold-contaminated feed treated with kaolin had the highest reduction of DON compared to the other adsorbents treatments (Table-4).

\section{Histopathology}

The liver sections from the birds fed with the basal feed showed normal histological features while birds that ate the mold-contaminated feed showed centric-lobular degeneration, necrosis, and fatty changes in the hepatocytes (Figure-1). The group fed mold-contaminated feed supplemented with $S$. cerevisiae showed distorted and acinar arrangement of hepatocytes while the group fed mold-contaminated feed supplemented with bentonite or kaolin showed nodular areas of lymphoid cell accumulation
(Figure-1). The kidney sections from the group fed mold-contaminated feed showed mild degeneration of the tubular epithelium while all the other treatment groups had normal histological features of the kidney (Figure-2). The sections of the spleen from the group fed the basal feed showed normal histological features compared to the group fed mold-contaminated feed which showed cellular depletion and degenerative changes in the white pulp of the germinal center while the groups fed mold-contaminated feed supplemented with either S. cerevisiae, bentonite or kaolin showed no observable histological changes (Figure-3). The bursa of Fabricius of the group fed basal feed showed normal histological features compared with the group fed mold-contaminated feed that showed mild to moderate lymphocytic depletion in their follicles. However, all the adsorbent treated groups showed edema and widened interfollicular septa of the bursa of Fabricius (Figure-4).

\section{Hematology and serum biochemistry}

Table-5 shows the results of the hematological analysis of the experimental birds. The group fed mold-contaminated feed had a significant $(p<0.05)$ decrease in RBC count, PCV, hemoglobin concentration, and increase in WBC count compared to the control group that ate the basal feed. Furthermore, the serum liver enzyme activity (ALT, AST, and ALP) and cholesterol concentration increased significantly $(\mathrm{p}<0.05)$ in the group fed mold-contaminated

Table-2: Biodiversity of the fungal contaminants in the feed.

\begin{tabular}{|c|c|c|c|c|c|}
\hline \multirow[t]{2}{*}{ Fungal contaminants } & \multicolumn{5}{|c|}{ Feed treatments } \\
\hline & Fresh feed & Con feed & Con feed + B & Con feed $+S$ & Con feed $+K$ \\
\hline Epicoccum sorghi & $x$ & $\checkmark$ & $\checkmark$ & $\checkmark$ & $\checkmark$ \\
\hline Rhizomucor pusillus & $x$ & $\checkmark$ & $\checkmark$ & $\checkmark$ & $\checkmark$ \\
\hline Pichia farinosa & $x$ & $\checkmark$ & $x$ & $x$ & $\checkmark$ \\
\hline Penicillium bilaiae & $x$ & $\checkmark$ & $x$ & $x$ & $\checkmark$ \\
\hline Penicillium crustosum & $x$ & $x$ & $\checkmark$ & $\checkmark$ & $x$ \\
\hline Penicillium glabrum & $x$ & $x$ & $x$ & $x$ & $\checkmark$ \\
\hline Aspergillus fumigatus & $x$ & $x$ & $x$ & $\checkmark$ & $x$ \\
\hline Aspergillus niger & $x$ & $\checkmark$ & $x$ & $x$ & $x$ \\
\hline Beauveria felina & $x$ & $x$ & $x$ & $\checkmark$ & $x$ \\
\hline
\end{tabular}

$\checkmark=$ Fungus present, $x=$ Fungus not present. Fungi were isolated based on their morphological characteristics and molecularly identified by sequencing of the ITS region. Con feed=Contaminated feed, Con feed $+\mathrm{S}=$ Contaminated feed+Saccharomyces cerevisiae, Con feed $+B=$ Contaminated feed+bentonite, Con feed+K=Contaminated feed + kaolin

Table-3: Fungi identified by ITS sequencing and their GenBank accession numbers.

\begin{tabular}{llcc}
\hline Sample identity & Fungi identity & Accession No & \% similarity \\
\hline Seq01a & Epicoccum sorghi & KC106688 & 79 \\
Seq02a & Rhizomucor pusillus & KY583064 & 99 \\
Seq03a & Pichia farinosa var. farinosa & FJ196777 & 99 \\
Seq04a & Penicillium bilaiae & KU574710 & 99 \\
Seq04c & Penicillium crustosum & KT192315 & 98 \\
Seq04d & Penicillium glabrum & EU128622 & 99 \\
Seq12 & Aspergillus fumigatus & MH345857 & 99 \\
Seq09 & Aspergillus niger & KR085975 & 99 \\
Seq14 & Beauveria felina & KF993397 & 89 \\
\hline
\end{tabular}

Fungi identified by PCR amplification of the Internal Transcribed Spacer Region (ITS rDNA) of the fungal isolates from the feed using the universal primers ITS1 and ITS4 followed by sequencing and blast search at NCBI database. Fungal sequences were deposited at GenBank with the accession numbers on the table 
feed while the serum total protein and albumin concentration decreased significantly $(p<0.05)$ in the same group (Figure-5). Inclusion of adsorbents in the mold-contaminated feed led to an increase in PCV, hemoglobin concentration, $\mathrm{RBC}$ count, and decrease in the WBC count. A decrease in ALT, AST, and ALP activity and cholesterol concentration and an increase in serum total protein and albumin concentration were observed in the adsorbent treated groups compared with the group fed mold-contaminated feed. However, the addition of kaolin and bentonite to the feed restored the hematological and serum biochemical parameters of the broilers (Table-5 and Figure-5).

Table-4: Mycotoxin concentration in the different feed treatments.

\begin{tabular}{lcc}
\hline Treatments & $\begin{array}{c}\text { Total aflatoxin } \\
(\boldsymbol{\mu g} / \mathbf{k g})\end{array}$ & $\begin{array}{c}\text { DON } \\
(\boldsymbol{\mu g} / \mathbf{k g})\end{array}$ \\
\hline Basal diet & 16.874 & 26.48 \\
Mold-contaminated feed & 53.272 & 634.5 \\
Mold-contaminated feed+SC & 33.04 & 409.5 \\
Mold-contaminated feed+B & 23.674 & 332.925 \\
Mold-contaminated feed+K & 18.154 & 251 \\
\hline
\end{tabular}

DON=Doxylevanelone, $\mathrm{SC}=$ Saccharomyces cerevisiae, $\mathrm{B}=$ Bentonite, $\mathrm{K}=$ Kaolin
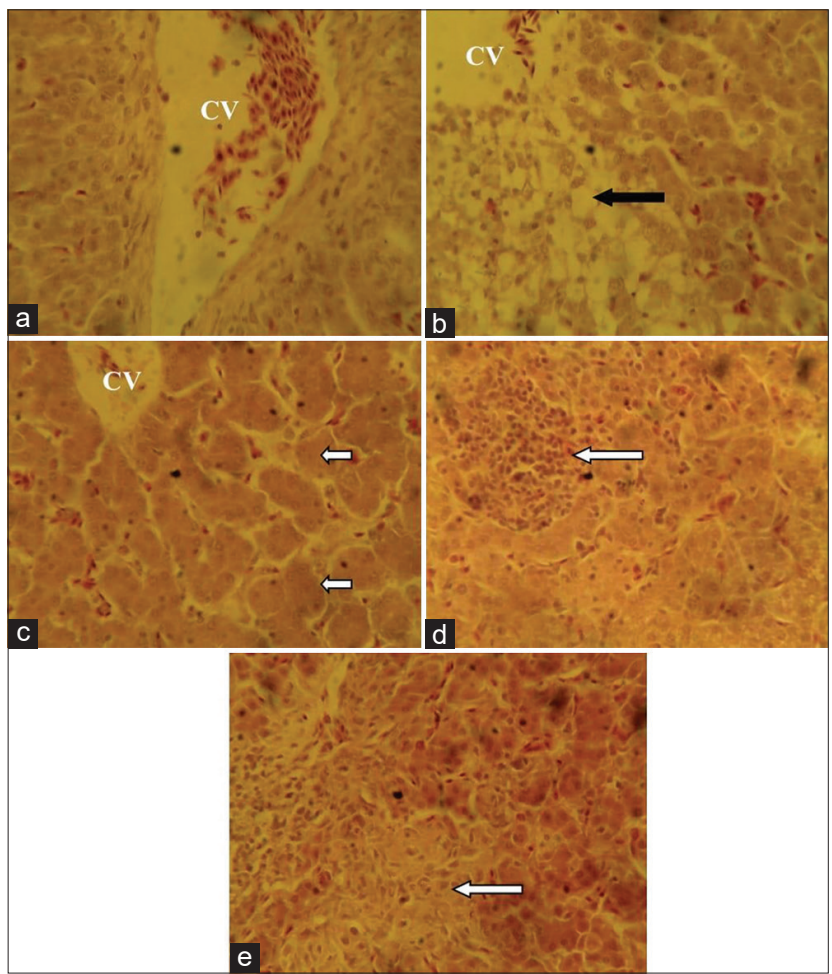

Figure-1: Photomicrograph of liver sections from the experimental groups: (a) Birds fed basal feed, showing normal histological features; (b) birds fed moldcontaminated feed showing centric-lobular degeneration and necrosis/fatty changes in hepatocytes (black arrows); (c) birds fed mold-contaminated feed+Saccharomyces cerevisiae, showing distorted and acinar arrangement of hepatocytes (short arrows) while (d) birds fed moldcontaminated feed+bentonite; and (e) birds fed moldcontaminated feed+kaolin, showing nodular areas of lymphoid cell accumulation (white arrows). See the CV (H and $\mathrm{E}, \times 400)$. CV $=$ Central vein.

\section{Discussion}

The commercial poultry feed used in the current study was treated in a way that promoted visible growth of fungal molds, and partly mimic the storage conditions in commercial broiler production in the tropics. The humidity introduced by sprinkling of water on the feed and the prevailing hot climate helped the growth of mycotoxin producing fungi [5]. The fungal growth induced the production of the identified mycotoxins; AF and DON. A very high concentration of AF was recorded in the mold-contaminated feed without adsorbent supplementation. A similar trend was observed for DON mycotoxin in the mold-contaminated feed. However, the addition of the three adsorbents to the feeds caused a drastic reduction of both mycotoxins. Kaolin had the highest mycotoxin reducing ability, followed by bentonite. Although not much is known in the literature on the mycotoxin degrading ability of kaolin, kaolin and bentonite are commonly used adsorbents because they lack primary toxicity. Their structural composition gives them a large surface area and better absorption capacity. S. cerevisiae showed the least efficacy in the decontamination of the mold-contaminated feeds. S. cerevisiae acts as a

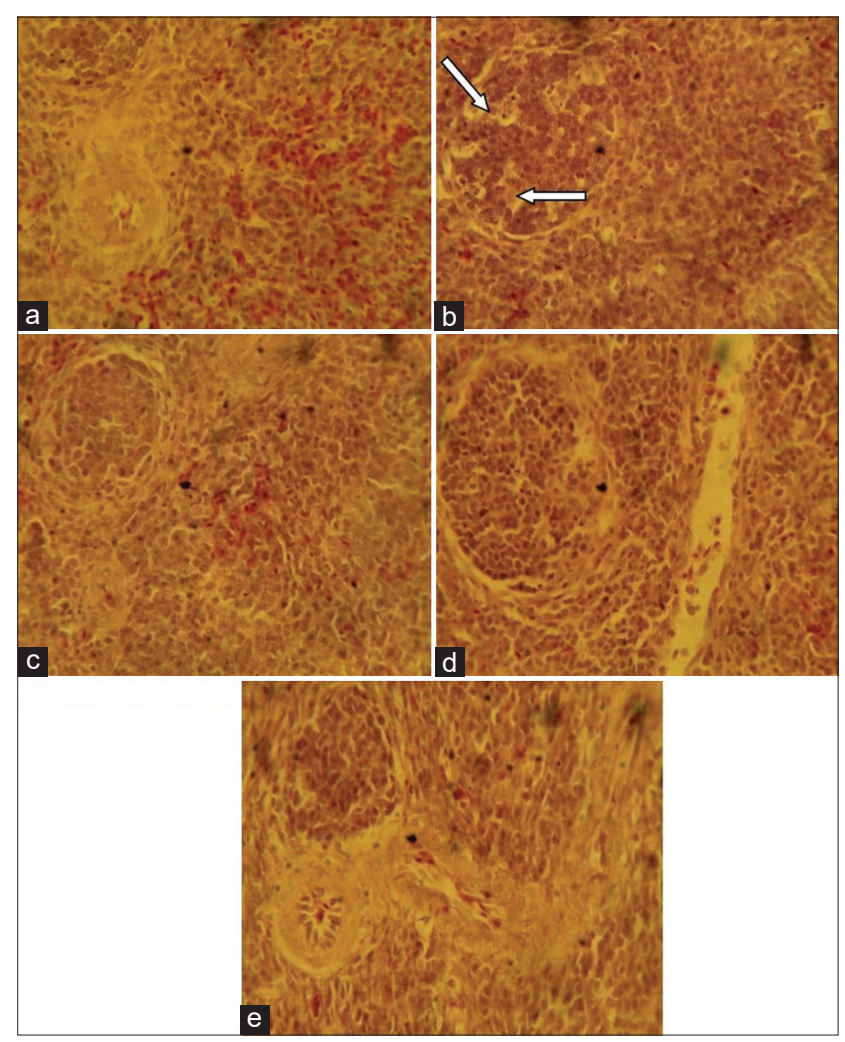

Figure-2: Photomicrograph of kidney sections from the experimental groups: (a) Birds fed basal feed, showing normal histological features; (b) birds fed moldcontaminated feed, showing mild degeneration of the tubular epithelium (arrows), while (c) birds fed moldcontaminated feed+Saccharomyces cerevisiae; (d) birds fed mold-contaminated feed+bentonite, and (e) birds fed mold-contaminated feed+kaolin show no observable histological change. See the GM ( $H$ and $E, \times 400)$. $\mathrm{GM}=$ Glomerulus. 

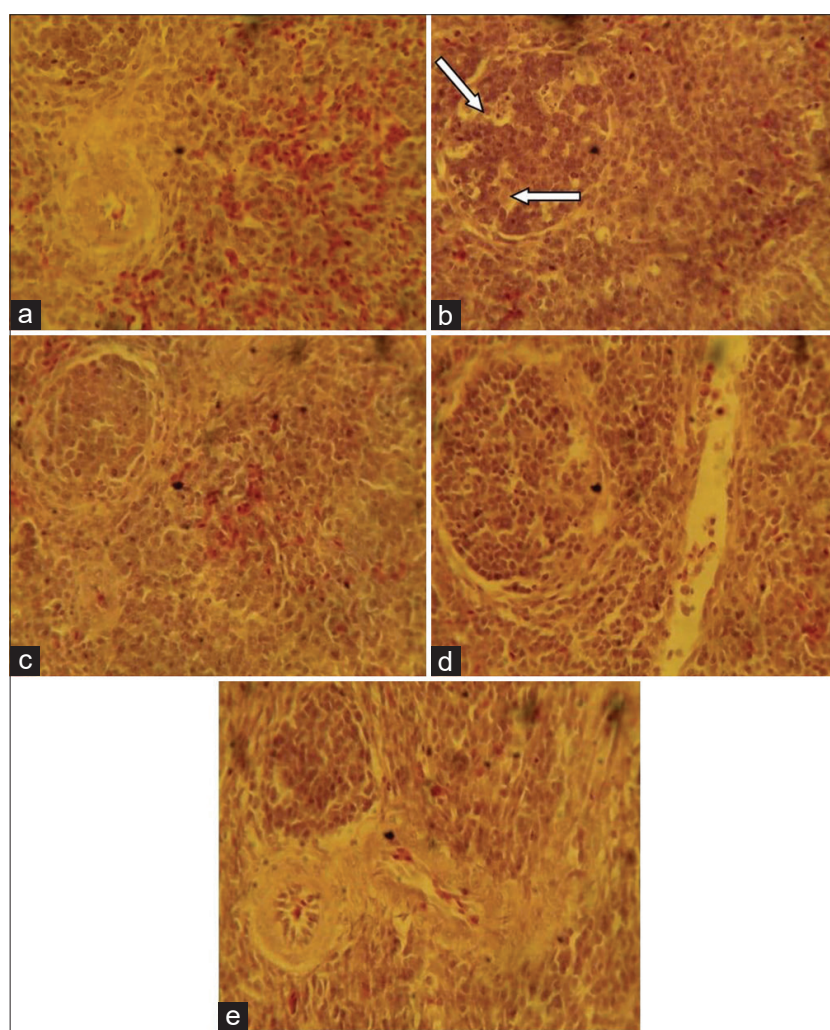

Figure-3: Photomicrograph of spleen sections from the experimental groups: (a) Birds fed basal feed, showing normal histological features, (b) birdsfed mold-contaminated feed, showing cellular depletion and degenerative changes in the white pulp of the germinal center (arrows), (c) birds fed mold-contaminated feed+Saccharomyces cerevisiae, (d) birds fed mold-contaminated feed+bentonite, and (e) birds fed Mold-contaminated feed+kaolin show no observable histological change $(H$ and $E, \times 400)$.

sequestering agent and forms mycotoxin-microorganism complex, and this excellent attribute makes it a good agent for biodegradation of mycotoxin in contaminated feeds $[20,24]$. A comparative study of the mycotoxin decontaminating ability of bentonite, activated charcoal and fuller's earth showed that bentonite had the highest efficacy and was able to lower the AF concentration of the feed from $120 \pm 38 \mu \mathrm{g} / \mathrm{kg}$ to $15 \pm 5.0 \mu \mathrm{g} / \mathrm{kg}$ [18]. S. cerevisiae was reported to bind $>60 \%$ of AFs in a study where the binding efficacy of different yeast isolates was determined. However, the microbes were reported to exhibit lower reducing activity compared to bentonite [39]. The basal feed had total AF level below the $20 \mu \mathrm{g} / \mathrm{kg}$ recommended by the United States food and Drug Administration but the concentration of DON in the feed was a little above this recommended level.

A wide range of fungal species from six different genera were found in the mold treated feed samples and also in the mold treated feeds supplemented with adsorbents. Two known mycotoxin producing fungi, Penicillium and Aspergillus species were prominent in the feed samples. Penicillium species are known to produce the mycotoxin; trichothecenes, including DON $[8,9]$. Aspergillus species are good producers of
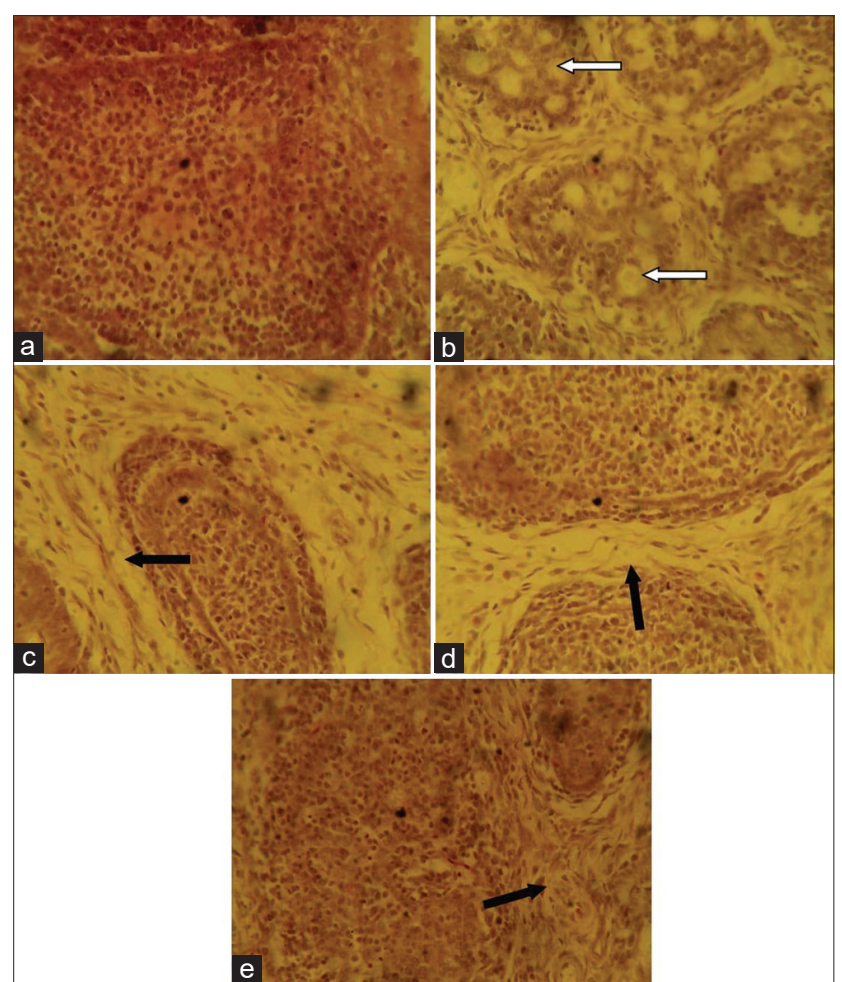

Figure-4: Photomicrograph of the bursa of Fabricius sections from the experimental groups: ( a) Birds fed basal feed, showing normal histological features; (b) birds fed mold-contaminated feed, showing mild-to-moderate lymphocytic depletion in their follicles (arrows), (c) birds fed mold-contaminated feed+Saccharomyces cerevisiea, (d) birds fed mold-contaminated feed+bentonite, and (e) birds fed Mold-contaminated feed+kaolin, show edema and widened interfollicular septa (black arrows) (H and $E$, $\times 400)$.

AFs [16]. In a previous study, feed samples exposed to the same conditions were contaminated with up to $120 \mu \mathrm{g} / \mathrm{kg}$ AFs (mainly $\mathrm{AFG}_{1}$ and $\mathrm{AFB}_{1}$ ), produced by a range of different Aspergillus [18]. It is, therefore, not surprising to observe high concentration of $\mathrm{AF}$ and DON in the feed samples. These mycotoxins may be the primary cause of the observed pathological changes in the birds.

Hemostasis and damage to blood system are major adverse effects associated with mycotoxicosis in animals [40]. In the present study, the mold-treated diet increased the WBC level of the birds by $44 \%$ but the $\mathrm{RBC}, \mathrm{Hb}$, and PCV were lowered by 55,56 , and $62 \%$, respectively. The reduction in $\mathrm{RBC}, \mathrm{PCV}$, and $\mathrm{Hb}$ levels may be an indication of anemic condition due to alteration of the hemopoietic processes by the mycotoxin [41]. The anemia may have occurred due to increased erythrocyte destruction in the hematopoietic organs, or the dysfunction of enzyme activities involved in heme biosynthesis [41]. The kaolin feed additive slightly improved the PCV, RBC, and Hb levels and decreased the WBC counts. The addition of bentonite also showed a positive effect on PCV, RBC, and WBC levels. This result is supported by data from supplementing AF-contaminated feed with $0.2 \%$ 


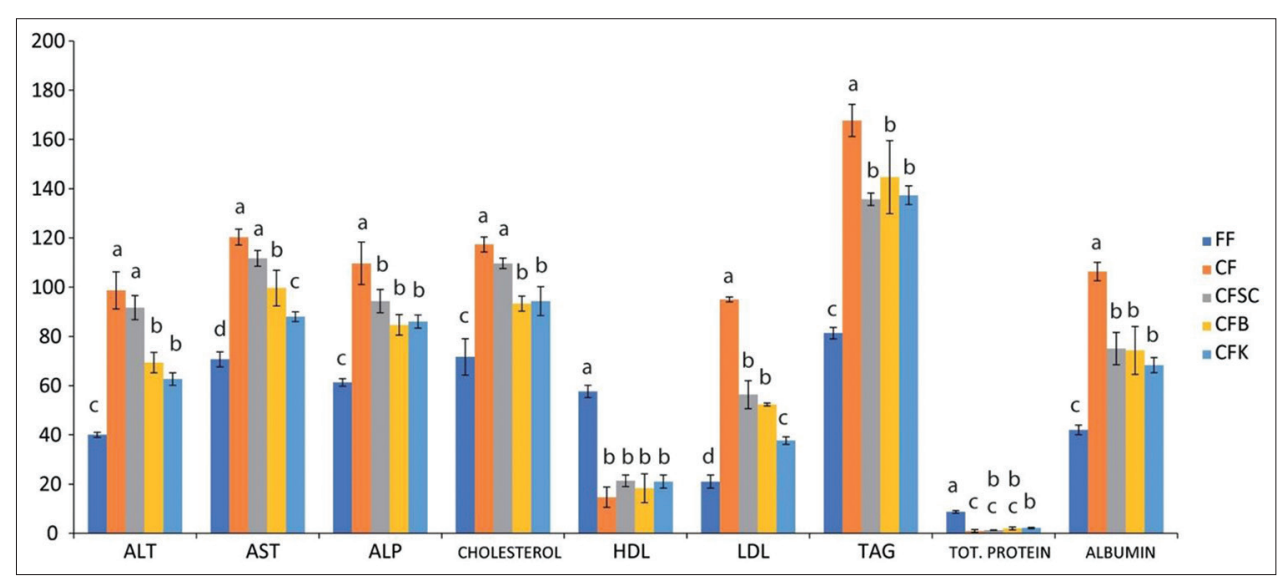

Figure-5: Serum biochemistry. Serum biochemical analysis of birds treated with mold-contaminated feed with or without adsorbent supplementation. (a) FF=Fresh feed/basal feed (negative control), (b) CF=Mold-contaminated feed, (c) CFSC=Mold-contaminated feed supplemented with Saccharomyces cerevisiae, (d) CFB=Mold-contaminated feed supplemented with bentonite (e) CFK=Mold-contaminated feed supplemented with kaolin. ALT=Alanine aminotransferase; $\mathrm{AST}=$ Aspartate aminotransferase; $\mathrm{ALP}=$ Alkaline phosphatase; $\mathrm{HDL}=$ High density; $\mathrm{LDL}=\mathrm{Low}$ density; $\mathrm{TAG}=$ Total Protein.

Table-5: Hematological parameters of broilers fed mold-contaminated feeds with or without Saccharomyces cerevisiae, bentonite or kaolin.

\begin{tabular}{lcccc}
\hline Treatments & PCV $(\%)$ & Hb $\mathbf{( g / d I )}$ & $\mathbf{R B C \times 1 0 6 / L}$ & $\mathbf{W B C \times 1 0 3 / L}$ \\
\hline Basal diet & $35.00 \pm 0.58^{\mathrm{a}}$ & $11.60 \pm 0.20^{\mathrm{a}}$ & $11.13 \pm 0.38^{\mathrm{a}}$ & $9.83 \pm 0.26^{\mathrm{a}}$ \\
Mold treated feed & $22.00 \pm 1.15^{\mathrm{c}}$ & $6.60 \pm 0.20^{\mathrm{c}}$ & $6.09 \pm 0.21^{\mathrm{c}}$ & $17.50 \pm 0.61^{\mathrm{b}}$ \\
Mold treated feed +SC & $24.33 \pm 1.20^{\mathrm{b}, \mathrm{c}}$ & $7.03 \pm 0.15^{\mathrm{b}, \mathrm{c}}$ & $7.21 \pm 0.21^{\mathrm{b}, \mathrm{c}}$ & $16.80 \pm 0.26^{\mathrm{b}}$ \\
Mold treated feed +B & $26.00 \pm 0.58^{\mathrm{b}}$ & $7.10 \pm 0.10^{\mathrm{b}, \mathrm{c}}$ & $8.08 \pm 0.21^{\mathrm{b}}$ & $14.60 \pm 0.40^{\mathrm{c}}$ \\
Mold treated feed +K & $26.67 \pm 0.8^{\mathrm{b}}$ & $7.97 \pm 0.49^{\mathrm{b}}$ & $8.34 \pm 0.15^{\mathrm{b}}$ & $13.60 \pm 0.26^{\mathrm{c}}$ \\
\hline
\end{tabular}

Means (mean \pm SEM) on the same row with different superscript are significantly different $(\mathrm{p}<0.05)$. PCV $=$ Packed cell volume, $\mathrm{Hb}=$ Hemoglobin, $\mathrm{RBC}=$ Red blood cell, $\mathrm{WBC}=$ White blood cell, $\mathrm{SC}=$ Saccharomyces cerevisiae, $\mathrm{B}=\mathrm{Bentonite}$, $\mathrm{K}=$ Kaolin

hydrated sodium calcium alumino silicate and $0.2 \%$ multi-mycosorbents [42]. However, in the current study, using $S$. cerevisiae as a feed additive had the least positive effect with regard to the blood parameters analyzed. Previously, certain $S$. cerevisiae strains were shown to bind $\mathrm{AFB}_{1}$ but there was a significant variation between strains that may explain the result in the current study [20]. The activity of AST increased by $42 \%$ while the ALT and ALP increased by 43 and $44 \%$, respectively, in the group fed mold-contaminated feed. The observed increase in the activity of the liver enzymes, AST, ALT, and ALP may be an indication of liver mycotoxicosis. Increases in activity of the liver enzymes have been reported previously in broilers fed AF-contaminated feed [18]. AFB 1 contaminated diets were reported to decrease levels of total cholesterol in ducklings [41]. However, in the present study, the cholesterol level was increased by the mold-contaminated feed. The variation in the results could be a result of species differences. While Filho et al. [41] used ducklings in their study, the present study was conducted using broilers.

The histopathological changes of the birds fed mold-contaminated feeds ranged from centric-lobular degeneration, necrosis, and fatty changes of the hepatocytes to mild degeneration of the tubular epithelium of the kidney. The spleen and bursa of Fabricius of the group fed mold-contaminated feeds showed moderate changes in the white pulp and follicles, respectively. The observed histopathological changes in these organs were consistent with the previous reports on the effects of mycotoxins in birds $[18,43]$. Birds experimentally treated with mycotoxin-contaminated feeds and those treated with contaminated feeds protected by adding 1\% Mycofix Plus showed comparable results. Histopathological sections of organs from both groups of birds showed extensive lesions in the positive control group while the Mycofix practically reduced the lesions in the protected group [26]. The liver histopathological changes were corroborated with the result from the serum biochemistry. Mycotoxins such as AFs have been reported to cause severe adverse effects in the liver, kidney, and lymphoid organs such as the spleen and bursa of Fabricius [10,44]. However, the various degrees of histopathological changes in the organs of birds fed the adsorbent treated feed showed the suppressive effects of the feed additives against the mycotoxins. This is consistent with similar reports on the ameliorative effects of $S$. cerevisiae cell wall and bentonite on broilers fed AF-contaminated feed [16]. Bentonite has been reported to have hepatoprotective and nephroprotective effects against mycotoxicosis [18]. Furthermore, reports have shown that bentonite, fuller's earth, and activated charcoal were able to prevent liver pathologies in birds fed AF-contaminated feed [18]. 


\section{Conclusion}

The results from this study show that kaolin has a more protective effect against mold-contaminated feed induced mycotoxicosis in broilers, followed by bentonite and lastly, by $S$. cerevisiae. The findings from this work could be useful to feed producers and poultry farmers as the adsorbents can be used as feed additives to enhance the efficiency and performance of birds if mycotoxin is suspected in feeds.

\section{Authors' Contributions}

TE contributed in conceptualizing the study, designing the work and supervision. ACM conceptualized the study, supervised it, helped in data analysis and wrote the manuscript. $\mathrm{CO}$ and AMU did part of the lab work. EIN helped with data analysis. IRO did the histopathological analysis, TD and MM did the molecular studies. MK did the data analysis and helped in manuscript preparation. All authors read and approved the final manuscript.

\section{Acknowledgments}

The authors acknowledge the efforts of the technical staff of the Department of Pathology and Microbiology, Faculty of Veterinary Medicine, University of Nigeria, Nsukka. The authors did not receive any funds for this study.

\section{Competing Interests} interests.

The authors declare that they have no competing

\section{Publisher's Note}

Veterinary World remains neutral with regard to jurisdictional claims in published institutional affiliation.

\section{References}

1. Heise, H., Crisan, A. and Theuvsen, L. (2015) The poultry market in Nigeria: Market structures and potential for investment in the market. Int. Food Agribus. Man. Rev., 18(10): 197-222.

2. Anne, M. G. and Tempio, G. T. (2017) Global poultry production: current state and future outlook and challenges. World's Poult. Sci. J., 73(2):1-12.

3. Murugesan, G.R., Ledoux, D.R., Naehrer, K., Berthiller, F., Applegate, T.J., Grenier B., Phillips, T.D. and Schatzmay, G. (2015) Prevalence and effects of mycotoxins on poultry health and performance, and recent development in mycotoxin counteracting strategies. Poult. Sci., 94(6): 1298-1315.

4. Nakavuma, J.L., Kirabo, A., Bogere, P., Nabulime, M.M., Kaaya, A.N. and Gnonlonfin, B. (2020) Awareness of mycotoxins and occurrence of aflatoxins in poultry feeds and feed ingredients in selected regions of Uganda. Int. $J$. Food Contam., 7:1.

5. Tai, B., Chang, J., Liu, Y. and Xing, F. (2020) Recent progress of the effect of environmental factors on Aspergillus flavus growth and aflatoxins production on foods. Food Qual. Saf., 4: 21-28.

6. Greeff-Laubscher, M.R., Beukes, I., Gert Johannes Marais G.J. and Jacobs, K. (2019) Mycotoxin production by three different toxigenic fungi genera on formulated abalone feed and the effect of an aquatic environment on fumonisins. Mycology, 11(2): 105-117.
7. del Palacio, A. and Pan, D. (2020) Occurrence and toxigenic potential of Aspergillus section Flavi on wheat and sorghum silages in Uruguay. Mycology, 11 (2): 147-157.

8. Chilaka, C.A., De Boevre, M., Atanda, O.O. and De Saeger, S. (2017) The status of Fusarium mycotoxins in Sub-Saharan Africa: A review of emerging trends and post-harvest mitigation strategies towards food control. Toxins, 9(1): 19

9. Bertero, A., Moretti, A., Spicer, L.J. and Caloni, F. (2018) Fusarium Molds and Mycotoxins: Potential SpeciesSpecific Effects. Toxins (Basel), 10(6): 244.

10. Peng, X., Bai, X., Ding, X., Zeng, Q., Zhang, K. and Fang, J. (2015) Pathological changes in the immune organs of broiler chickens fed on corn naturally contaminated with aflatoxins B1 and B2. Avian Pathol., 44(3): 192-199.

11. Kiran, S., Surekha, M., Benarjee, G., Ram Reddy, R. and Reddy, S.M. (2015) Haematological and biochemical changes in chicks fed with Aspergillus terreus infested feed. Asian J. Poult. Sci., 9(3): 172-178.

12. Monson, M., Coulombe, R.A. and Reed, K.M. (2015) Aflatoxicosis: Lessons from Toxicity and Responses to Aflatoxin B1 in Poultry. Agriculture, 5(3):542-777.

13. Ostry, V., Malir, F., Toman, J. and Grosse, Y. (2017) Mycotoxins as human carcinogens-the IARC monographs classification. Mycotoxin. Res., 33(1): 65-73.

14. Colovic, R., Puvača, N., Cheli, F. and Pinotti, F. (2019) Decontamination of mycotoxin-contaminated feedstuffs and compound feed. Toxins, 11(11): 617

15. Adebo, O.A., Njobeh, P.B., Gbashi, S., Nwinyi O.C. and Mavumengwana, V. (2017) Review on microbial degradation of aflatoxins. J. Crit. Rev. Food Sci., 57(15): 3208-3217.

16. Haider M.S., Murtaza, S., Jamil, M., Hameed, A., Abbass, M.I., Joya, M.H., Ihsan, M., Ali, M., Ahmad, L. and Khattak, I. (2015) Comparison of ameliorative potential of saccharomyces cerevisiae and bentonite clay on pathological effects induced by aflatoxin in broiler. Sci. Int., 27(6): 6077-6085.

17. Oguz, H., Bahçivan, E. and Erdoğan, T. (2018) Detoxification of aflatoxin in poultry feed: An update. Eur. J. Vet. Sci., 34(4): 204-227.

18. Mgbeahuruike, A.C., Ejioffor, T.E., Obasi, C.C., Shoyinka, V.O., Karlsson, M. and Nordkvist, E. (2018) Detoxification of aflatoxin-contaminated poultry feeds by 3 adsorbents, bentonite, activated charcoal, and fuller's earth. J. Appl. Poult. Res., 27(4): 461-471.

19. Bhatti, S.A., Khan, M., Hassan, Z., Kashif, M., Saqib, M., Khatoon, A. and Akhter, M. (2018) Comparative efficacy of Bentonite clay, activated charcoal and Trichosporon mycotoxinivorans in regulating the feed-to-tissue transfer of mycotoxins. J. Sci. Food Agric., 98(3): 884-890.

20. Chlebicz, A. and Śliżewska, K. (2020) In vitro detoxification of aflatoxin B1, deoxynivalenol, fumonisins, T-2 toxin and zearalenone by probiotic Bacteria from genus Lactobacillus and Saccharomyces cerevisiae yeast. Probiotics Antimicro. Proteins, 12(1): 289-301.

21. Zhu, Y., Hassan, Y.I., Lepp, D., Shao, S. and Zhou, T. (2017) Strategies and methodologies for developing microbial detoxification systems to mitigate mycotoxins. Toxins, 9(4): 130.

22. Juodeikiene, G., Bartkiene, E., Cernauskas, D., Cizeikiene, D., Zadeike, D., Lele, V. and Bartkevics, V. (2018) Antifungal activity of lactic acid Bacteria and their application for Fusarium mycotoxin reduction in malting wheat grains. LWT Food Sci. Technol., 89(3): 307-314.

23. El-Shall, N.A., Awad, A.M., Abd El-Hack, M.E., Naiel, M.E.A., Othman, S.I., Allam, A.A. and Sedeik, M.E. (2019) The simultaneous administration of a probiotic or prebiotic with live Salmonella vaccine improves growth performance and reduces fecal shedding of the bacterium in Salmonella-challenged broilers. Animals, 10(1): 70.

24. Arif, M., Iram, A., Bhutta, M.A.K., Naiel, M.A.E, Abd El-Hack, M.E., Othman, S.I., Allam, A.A., Amer, M.S. and Taha, A.E. (2020) The biodegradation role of 
Saccharomyces cerevisiae against harmful effects of mycotoxin contaminated diets on broiler performance, immunity status, and carcass characteristics. Animals, 10(2): 238.

25. Nadziakiewicza, M., Kehoe, S. and Micek, P. (2019) Physicochemical properties of clay minerals and their use as a health-promoting feed additive. Animals (Basel), 9(10): 714.

26. Karp, N.A., Meehan, T.F., Morgan, H., Mason, J.C., Blake, A., Kurbatova, N., Smedley, D., Jacobsen. J., Mott, R.F., Iyer, V., Matthews, P., Melvin, D.G., Wells, S., Flenniken, A.M., Masuya, H., Wakana, S., White, J.K., Lloyd, K.C.K., Reynolds, C.L., Paylor, R., West, D.B., Svenson, K.L., Chesler, E.J., de Angelis, M.H., TocchiniValentini, G.P., Sorg, T., Herault, Y., Parkinson, H., Mallon, A.M., Brown, S.D.M. (2015) Applying the ARRIVE guidelines to an in vivo database. PLoS Biol., 13(5): e1002151.

27. National Population Commission. (2018) Nigerian Demographics and Health Survey. Available from: https:// www.dhsprogram.com/pubs/pdf/FR359/FR359.pdf. Retrieved on 02-04-2020.

28. National Research Council. (2019) Nutrient Requirements of Poultry. $10^{\text {th }}$ ed. Conference Call, National Research Council, United States.

29. Aziza, N.H. and Zainol, N. (2018) Isolation and identification of soil fungi isolates from forest soil for flooded soil recovery. IOP Conf. Ser. Mater. Sci. Eng., 342(1): 012028.

30. Sharma, A.K., Sharma, V., Saxena, J., Yadav, B., Alam, A. and Prakash, A. (2015) Isolation and screening of extracellular protease enzyme from bacterial and fungal isolates of soil. Int. J. Sci. Res. Environ. Sci., 3(9): 334-340.

31. Ravimannan, N., Pathmanathan, S. and Saarutharsha, S. (2016) Study on fungi associated with spoilage of bread. Int. J. Adv. Res. Biol. Sci., 3(4): 165-167.

32. Tkacz, A., Hortala, M. and Poole, P.S. (2018) Absolute quantitation of microbiota abundance in environmental samples. Microbiome, 6(1): 110.

33. Raja, H.A, Miller, A.N., Pearce, C. and Oberlies, N.H. (2017) Fungal identification using molecular tools: A primer for the natural products research community. J. Nat. Prod., 80(3): 01085.

34. Chen, Y., Ye, W., Zhang, Y. and Xu, Y. (2015) High speed BLASTN: An accelerated MegaBLAST search tool. Nucleic Acids Res., 43(16): 7762-7768.

35. Carisch, L., Stirn, M., Hatt, J.M., Federer, K., Hofmann-Lehmann, R. and Riond, B. (2019) White blood cell count in birds: Evaluation of a commercially available method. BMC Vet. Res., 15(1): 8.

36. Rezende, M.S., Mundim, A.V., Fonseca, B.B., Miranda, R.L., Oliveira, W. and Lellis, C.G. (2017) Profile of serum metabolites and proteins of broiler breeders in rearing age. Braz. J. Poult. Sci., 19(4): 583-586.

37. Corso, G., Papagni, F., Gelzo, M., Gallo, M., Barone, R., Graf, M., Scarpato, N. and Dello, A. (2016) Development and validation of an enzymatic method for total cholesterol analysis using whole blood spot. J. Clin. Lab. Anal., 30(5): 517-523.

38. Bancroft, J.D. and Gamble, M. (2008) Theory and Practice of Histological Techniques. $6^{\text {th }}$ ed. Churchill Livingstone Elsevier, Philadelphia, PA, USA.

39. Gul, H., Khan, S., Shah, Z., Ahmad, S., Israr, M. and Hussain, M. (2017) Effects of local sodium bentonite as AF binder and its effects on production performance of laying hens. Kafkas Üniv. Vet. Fak. Derg, 23(1): 31-37.

40. Huang, S., Zheng, N., Fan, C., Cheng, M., Wang, S., Jabar, A., Wang, J. and Cheng, J. (2018) Effects of aflatoxin B1 combined with ochratoxin A and/or zearalenone on metabolism, immune function, and antioxidant status in lactating dairy goats. Asian Aust. J. Anim. Sci., 31(4): 505-513.

41. Filho, S.T.S., Junqueira, O.M., de Laurentiz, A.C., da Silva Filardi, R., da Silva Rubio, M., Duarte, K.F. and da Silva de Laurentiz, R. (2016) Effects of mycotoxin adsorbents in aflatoxin B 1-and fumonisin B 1-contaminated broiler diet on performance and blood metabolite. R. Bras. Zootec., 45(5): 250-256.

42. Rattanasinthuphong, K., Tengjaroenkul, B., Tengjaroenkul, U. and Pakdee, P. (2017) Efficacy of mycosorbents to ameliorate the adverse effects of natural aflatoxin contamination in the diets of Cherry Valley ducks. Livest. Res. Rural Dev., 29(3): 48.

43. Khetmalis, R.S., More, B.K., Mote, C.S., Jadhav, S.N., Kamdi, B.P. and Dhaygude, V.S. (2018) Experimental study on pathology of aflatoxicosis in broiler chicks and its amelioration by Emblica officinalis (Amla) supplementation. Int. J. Livest. Res., 8(10): 287-297.

44. Śliżewska, K., Cukrowska, B., Smulikowska, S. and Cielecka-Kuszyk, J. (2019) The effect of probiotic supplementation on performance and the histopathological changes in liver and kidneys in broiler chickens fed diets with aflatoxin B1. Toxins, 11(2): 112. 